\title{
Prevalence of slaughter and liver condemnation due to Fasciola hepatica among sheep in the state of Rio Gran- de do Sul, Brazil 2000 and 2005
}

\author{
FABÍOLA OPITZ VIEIRA DA CUNHA* ; SANDRA MÁRCIA TIETZ MARQUES ** e MARY JANE \\ TWEEDIE DE MATTOS***
}

\begin{abstract}
The aim of this study is to determine the prevalence of Fasciola hepatica among sheep in the state of Rio Grande do Sul, Brazil, by reviewing slaughter and liver condemnation data obtained from the Federal Inspection Service, affiliated with the Brazilian Ministry of Agriculture, Animal Husbandry and Supply, for years 2000 to 2005. Liver condemnation amounted to $14.57 \%(18,072 /$ $124,078)$ in $2000,10.14 \%(11,998 / 118,332)$ in $2001,10.96 \%(11,372 / 103,762)$ in $2002,9.96 \%(10,802 /$ $108,461)$ in 2003, $5.42 \%(6,245 / 114,596)$ in 2004 , and $2.27 \%(2,750 / 121,172)$ in 2005 . The overall prevalence of liver condemnation due to $\boldsymbol{F}$. hepatica corresponded to $8.87 \%$ (61.239/690.361). In conclusion, fascioliosis was found to be prevalent among sheep in the state of Rio Grande do Sul and to account for major economic losses to farmers, meat packing plants and to the government.
\end{abstract}

Key words: Fasciola hepatica, sheep, liver condemnation, prevalence

\section{INTRODUÇÃO}

A fasciolose é uma zoonose parasitária produzida pelo trematódeo Fasciola hepatica e de importância econômica devido às perdas causadas por condenações de fígados em abatedouros-frigoríficos, mortalidade, redução na produção de lã, carne e leite, infecções secundárias, perda de peso, interferência na fertilidade e custos com tratamentos antihelmínticos ${ }^{1,2}$. A mortalidade é importante em ovinos e bovinos e pode representar, em locais contaminados, perdas significativas em torno de 15 a $20 \%{ }^{3}$.
No Brasil, as áreas mais atingidas pela $F$. hepatica estão localizadas no Rio Grande do Sul, Santa Catarina, Paraná, São Paulo, Minas Gerais, Rio de Janeiro e Goiás ${ }^{4-8}$.

Fasciola hepatica tem alta freqüência no Rio Grande do Sul, especialmente no sul e sudeste do Estado, onde a fasciolose é endêmica. A ocorrência desta parasitose está ligada a presença de moluscos do gênero Lymneae, hospedeiro intermediário, bem como de ovinos e bovinos parasitados, hospedeiros definitivos, os quais são disseminadores de ovos. A topografia, hidrografia, como a presença das Lagoas dos Patos, Mirim e Mangueira, banhados, pastagens alagadiças e

* Médica Veterinária, Faculdade de Veterinária (FAVET), Universidade Federal do Rio Grande do Sul (UFRGS). Monografia apresentada como requisito para obtenção do grau de Médica Veterinária.

** Profa. MSc, Dr., Departamento de Patologia Clínica Veterinária, FAVET, UFRGS. Rua Aneron Corrêa de Oliveira, 74, ap. 201, Bairro Jardim do Salso, Porto Alegre, Rio Grande do Sul, Brasil. CEP: 91.410-070.

*** Profa. MSc, Dr., Departamento de Patologia Clínica Veterinária, FAVET, UFRGS, Brasil. 
restevas da orizicultura irrigada, contribuem na disseminação e manutenção da alta freqüência de fasciolose o ano todo 9,10 .

Informações sobre condenações de fígados parasitados por F. hepatica em animais são baseados em dados fornecidos pelos frigoríficos abatedouros, através do Serviços de Inspeção Federal (SIF), Serviço de Inspeção Estadual ou Municipal.

A Região Sul do Brasil tem um plantel ovino de 4.515.766 cabeças, totalizando $29,99 \%$ do efetivo entre as 5 regiões geográficas ${ }^{11}$. Por Estado da federação, o Rio Grande do Sul detém o ranking de maior rebanho ovino no período de 2005, totalizando em torno de 4 milhões de cabeças. No crescimento percentual do rebanho de ovinos, por região, no período de 1998 a 2004, a Região Sul teve um decréscimo de $23,74 \%$, enquanto as outras regiões tiveram um crescimento médio de $31,46 \%{ }^{12}$.

Em 2005, o número de abates de ovinos sob controle do Serviço de Inspeção do Ministério da Agricultura, Pecuária e Abastecimento foi de 121.180 cabeças e foi estimado, para o ano de 2006, o abate de 63.830 cabeças ${ }^{13}$.

O Rio Grande do Sul apresenta um percentual de condenações de fígados que tem aumentado. Entre os anos de 1958 a 1963, a fasciolose bovina obteve índices de 8\% e para os anos 1974 até 1977 foi de $11,5 \%{ }^{14}$. Em 1984 a prevalência foi de $14,7 \%$, quando 142.980 fígados foram condenados devido à $F$. hepatica, com prejuízo para a indústria e produtores ${ }^{3}$.

Levantamento sobre fasciolose bovina no Estado do Rio Grande do Sul, dos anos de 1993 a 1997, demonstrou prevalência geral de 13,2\% de fígados condenados em matadourosfrigoríficos e percentuais elevados nos municípios de Santa Vitória do Palmar (38\%), Cristal (37,8\%), Camaquã e Herval (19\%). Nos municípios de Bagé, Dom Pedrito, São Lourenço do Sul, Rio Grande, Arroio Grande, Tapes, Ulha Negra, Pinheiro Machado, Canguçú, Encruzilhada do Sul, Caçapava do Sul, Candiota, Lavras do Sul, Amaral Ferrador e Cruz Alta, a prevalência variou entre 10 a $15 \%$. Para ovinos, a prevalência de condenação de fígados parasitados foi de $4 \%$, entre os anos de 1993 e $1997^{15}$

Para as espécies bovina e bubalina, as prevalências de condenações de fígados parasitados por F. hepatica foram de 10,34\% e $20 \%$, respectivamente. Por procedência das amostras, representou uma positividade de $63,6 \%$ e de $80 \%$, respectivamente, de municípios do Rio Grande do Sul, a maioria deles com relatos anteriores da presença da $F$. hepatica ${ }^{16}$.

Os dados mais recentes, divulgados para o Rio Grande do Sul, para a espécie bovina, foram dos anos de 2004 e 2005 com prevalência de $19,11 \%$ e $19,60 \%$, respectivamente. Entretanto, dados na literatura sobre a condenação de fígados por fasciolose ovina no Rio Grande do Sul e no resto do país são escassos. Os dados são gerados, porém o acesso às informações é restrito à indústria e aos produtores. Um dos raros relatos em condenação de fígados por fasciolose em ovinos, são dos anos de 1983 e 1984, com prevalência de $11 \%$ e $9,1 \%$, respectivamente ${ }^{5}$.

O objetivo deste trabalho foi determinar a prevalência de condenações de fígados ovinos parasitados por $F$. hepatica, de animais provenientes de diversas regiões do Estado, dos anos de 2000 a 2005.

\section{MATERIAL E MÉTODOS}

Foram coletados dados de planilhas de controle de abate e de condenações de fígados ovinos, em matadouros-frigoríficos no Estado do Rio Grande do Sul, avaliados pelo Serviço de Inspeção Federal do Ministério da Agricultura, Pecuária e Abastecimento, entre anos de 2000 a 2005. As informações foram obtidas de animais de ambos os gêneros e idades variadas, totalizando 690.361 abates.

\section{RESULTADOS E DISCUSSÃO}

$\mathrm{O}$ resultado do número de ovinos abatidos e de condenação de fígados por $F$. hepatica, obtidos do Serviço de Inspeção Federal (SIF) do Ministério da Agricultura, Pecuária e Abastecimento do Estado do Rio Grande do Sul é mostrado na

Os municípios com maior percentual de fasciolose, nos anos amostrados, e obtidos através de condenação de fígados foram: Santa Vitória do Palmar, Santo Antônio da Patrulha, Osório, Terra de Areia, Tapes, Vacaria e Cachoeira do Sul. Ao analisar estes dados, nota-se um decréscimo nos índices percentuais, o que é satisfatório, embora não seja um dado realista, pois uma parcela significativa de ovinos não se encontra neste percentual, como animais de 
cabanha, animais ainda em fase de crescimento e terminação para o abate. Além disso, o consumo de carne ovina é preferencial nas fazendas, é de menor custo e praticado tradicionalmente na propriedade, com abates in loco. Falta, no entanto, estrutura para abate. É preocupante, principalmente pelo fato dos abates clandestinos ocorrerem e serem em número elevado. De acordo com o Ministério da Agricultura, Pecuária e Abastecimento do Rio Grande do Sul, é estimado que para cada 10 animais abatidos em matadouros-frigoríficos, outros 6 são abatidos clandestinamente ${ }^{13}$. Mesmo recebendo denúncias, os fiscais do Serviço de Inspeção pouco ou nada podem fazer. É difícil confirmar as denúncias tendo em vista que as propriedades abatem para consumo próprio. Muitas vezes o abate é dificultado pela própria legislação, que só permite a entrada dos fiscais com ordem judicial. Uma solução para estes casos, seria a institucionalização de abates comunitários, que reduziriam os problemas sanitário e financeiro, e ajudaria o faturamento de estabelecimentos legalizados. $\mathrm{O}$ empecilho deste tipo de abate é antes de tudo convencer os proprietários dos animais a abater em locais apropriados e conscientizá-los dos perigos dos abates clandestinos.

A demanda por carne ovina vem apresentando crescimento considerável nas grandes cidades brasileiras, porém este consumo ainda é considerado baixo, em relação ao consumo de carne de bovinos, frangos e suínos. Perdas também em relação ao abate, ocorrem por vantagens competitivas de outros estados, tais como: solo, pasto, melhores canais de distribuição, incentivos fiscais e infra-estrutura de maior aporte para abates.

Frente a isto, existe também a insegurança alimentar quanto à ingestão de produtos cárneos ovinos e sua possível transmissão de doenças para humanos.

Em algumas regiões do Estado, as características geográficas contribuem para a manutenção do hospedeiro intermediário. O manejo de criação, que coloca animais a pasto por longos períodos e o consórcio de pastejo com bovinos também são importantes na manutenção da fasciolose.

O controle eficiente da fasciolose requer uma correta integração na redução do número de hospedeiros intermediários, pelo emprego de métodos químicos, físicos e biológicos. O combate ao molusco é praticamente impossível pelo seu alto poder biótico; sua erradicação é difícil porque o uso de molusquicidas representa grande perigo de contaminação para o meio ambiente; e a drenagem, que nem sempre é possível, devido à extensão das áreas contaminadas e mesmo porque, em muitos casos, essas áreas consistem dos próprios canais de irrigação da lavoura agrícola $^{3}$.

Para o controle eficiente desta parasitose é necessário o uso de fasciolicidas que sejam de fácil aplicação, de baixo custo, não sejam tóxicos, que não deixem resíduos e que sejam altamente eficazes no combate às fases adultas e imaturas da $F$. hepatica. A freqüência das medicações irá depender da eficiência do medicamento e do grau de exposição dos animais em áreas altamente contaminadas.

Ao adquirir animais em feiras, exposições ou compra direta do pecuarista, o criador deve exigir a certificação da sanidade dos ovinos quanto às verminoses. Deverá, ao introduzir animais novos na propriedade, fazer a dosificação estratégica e a quarentena dos animais. Na prática, o controle supressivo se torna muito caro, entretanto deveria ser utilizado em áreas contaminadas, como em algumas regiões do Rio Grande do Sul, onde a epidemiologia da doença é conhecida e a ocorrência de fasciolose é aguda.

Normalmente na Região Sul do Rio Grande do Sul, existe a indicação de duas medicações anuais para controlar a fasciolose, uma no final de outono e outra no início da primavera, possibilitando a eliminação de infecções adquiridas durante o verão e inverno. Além dessas medicações, é recomendada uma terceira dose estratégica, administrada no verão (dezembro ou

Tabela 1. Dados do Serviço de Inspeção Federal (SIF) do Ministério da Agricultura, Pecuária e Abastecimento (MAPA) do Rio Grande do Sul, Brasil, para ovinos abatidos e condenação de fígados por Fasciola hepatica, 2000-2005.

\begin{tabular}{lccc}
\hline ANO & Ovinos abatidos & \multicolumn{2}{c}{ Figados condenados } \\
& & $\mathrm{n}$ & $\%$ \\
\hline 2000 & 124.038 & 18.072 & 14,57 \\
2001 & 118.332 & 11.998 & 10,14 \\
2002 & 103.762 & 11.372 & 10,96 \\
2003 & 108.461 & 10.802 & 9,96 \\
2004 & 114.596 & 6.245 & 5,45 \\
2005 & 121.172 & 2.750 & 2,27 \\
Total & $\mathbf{6 9 0 . 0 0 0}$ & $\mathbf{6 1 . 2 3 9}$ & $\mathbf{8 , 8 7}$ \\
\hline
\end{tabular}


janeiro). Este programa estratégico permite que os animais, durante a fase de boa disponibilidade alimentar no campo nativo ou forragens (setembro a abril), estejam em boas condições sanitárias, para melhor conversão alimentar e assim, reduzir perdas de produção, condenações de vísceras, aproveitamento de cio, lactação e lã de melhor qualidade. Entretanto, são recomendações de ordem geral, porque em diferentes regiões do Estado, existem propriedades com diferentes níveis de parasitismo, cabendo ao médico veterinário, baseado em informações de abate e de exames parasitológicos, a recomendação específica para cada propriedade.

Conclui-se que a fasciolose ovina é prevalente no Rio Grande do Sul, acarretando perdas para os produtores, matadouros-frigoríficos e para o Estado.

\section{RESUMO}

O objetivo deste trabalho foi determinar a prevalência de Fasciola hepatica em ovinos no Estado do Rio Grande do Sul, Brasil, através de laudos de abate e condenação de fígados ovinos. Os dados de condenação de 2000 a 2005 foram obtidos do Serviço de Inspeção Federal (SIF) do Ministério da Agricultura, Pecuária e Abastecimento (MAPA). No ano de 2000 foi de $14,57 \%$ (18.072/124.078); em 2001 foi de $10,14 \%$ (11.998/118.332); em 2002 foi de $10,96 \%$ (11.372/103.762); em 2003 foi de $9,96 \%$ (10.802/108.461); em 2004 foi de 5,42\% (6.245/ 114.596) e em 2005 foi de 2,27\% (2.750/ 121.172). A prevalência geral de condenação de fígados por $F$. hepatica foi de 8,87\% (61.239/ 690.361). Conclui-se que a fasciolose ovina é prevalente no Rio Grande do Sul, acarretando perdas para os produtores, frigoríficos e para o Estado.

\section{REFERENCIAS}

1.- ROSS, J.G.; DOW, C.; TODD, J.R. A study of Fasciola hepatica infections in sheep. Veterinary Record 1997; 80: 543-6.

2.- DALTON J P. Fasciolosis. 1. ed. Cambrige, UK: University Press, 1999. p. 113-149.

3.- ECHEVARRIA F A M. Mesa Redonda sobre fasciolose
Bovina. A Hora Veterinária, Ed. Extra, n.1, p.2731,1995.

4.- UENO H, GUTIERRE V C, MATTOS M J T, MULLER G. Fasciolosis problems in ruminants in Rio Grande do Sul, Brazil. Veterinary Parasitology, 1982; 11(2-3): 185-91.

5.- ECHEVARRIA F A M. Fasciolose. Ocorrência, diagnóstico e controle. Agroquímica Ciba- Geigy 1985; 27: 4-9.

6.- AMATO S B, REZENDE H E B de, GOMES D C, SERRA- FREIRE N M. Epidemiology of Fasciola hepatica infection in the Paraíba River Valley, São Paulo, Brazil. Veterinary Parasitology 1986; 22: 27584.

7.- SERRA-FREIRE N M, BORDIN E L, LESSA C S S, et al. Reinvestigação sobre Fasciola hepatica no Brasil. A Hora Veterinária, Ed. Extra, n. 1, p. 19-21, 1995.

8.- SERRA-FREIRE N M. Fasciola hepatica. A Hora Veterinária, Ed. extra, n. 1, p.13-18, 1995.

9.- MATTOS M J T de, UENO H, GONÇALVES P C, ALMEIDA J E M de. Ocorrência estacional e bioecologia de Lymnaea columella Say, 1817 em habitat natural no Rio Grande do Sul. Revista Brasileira de Medicina Veterinária, 1997; 19: 248-52.

10.- MÜLlER G, JESUS L P de, PAULSEN R M M, SOUZA C A. Prevalência de fasciolose no sul do Rio Grande do sul. In: II Congresso de Medicina Veterinária do Cone sul, XII Congresso Estadual de Medicina Veterinária e XXV Congresso Brasileiro de Medicina Veterinária, 1997, Gramado. Resumos. Porto Alegre: Sociedade Brasileira de Medicina Veterinária.

11.- EMBRAPA - Empresa Brasileira de Pesquisa Agropecuária. 2006. Disponível em:< http:// www.cnpc.embrapa.br/catalogo.htm $>$ Acesso em: 20 .set. 2007.

12.- BRASIL, Instituto Brasileiro de Geografia e Estatística/Sidra. 2006. Disponível em: < http:// www.sidra.ibge.gov.br/bda/ pecua.> Acesso em: 20. set. 2007.

13.- BRASIL, Ministério da Agricultura, Pecuaria e Abastecimento. 2006. Disponível em: < http:// www.agricultura.gov.br/pls/portal/docs/page/mapa/ estatisticas/pecuaria/3.5.xls > Acesso em: 20. set. 2007.

14.- REZENDE H E B de. Retrospectiva da fasciolose bovina no Brasil. In: Seminário Nacional Sobre Parasitoses dos Bovinos, 1979, Campo Grande. Resumos. Campo Grande: Empresa Brasileira de pesquisa agropecuária/ Centro Nacional de Pesquisa de Gado de Corte, 1979, p. 133-43.

15.- MULLER G, BERNE M E A, RAFFI L L, et al. Influência da temperatura na longevidade de metacercárias de Fasciola hepatica. Revista Brasileira de Agrociência, 1999; 5(2): 164-5.

16.- MARQUES S M T, SCROFERNEKER M L. Fasciola hepatica infection in cattle and buffaloes in the State of Rio Grande do Sul, Brazil. Parasitología Latinoamericana 2003; 58(3-4): 169-72. 